TABLE 1. LV dimension/function and leaflets geometry

\begin{tabular}{|c|c|c|c|c|}
\hline & Variable & Preoperatively & Postoperatively & $P$ value \\
\hline \multirow{8}{*}{ LV } & MR (grade) & $3.5 \pm 0.5$ & $0.5 \pm 0.6$ & $<.001$ \\
\hline & LVDd (mm) & $63.2 \pm 8.2$ & $58.6 \pm 5.7$ & $<.005$ \\
\hline & LVEF $(\%)$ & $25.1 \pm 6.9$ & $29.8 \pm 10.6$ & NS \\
\hline & Tenting area $\left(\mathrm{cm}^{2}\right)$ & $1.7 \pm 0.6$ & $0.6 \pm 0.1$ & $<.001$ \\
\hline & AML angle $\left({ }^{\circ}\right), * 1$ & $42.9 \pm 8.5$ & $26.3 \pm 9.2$ & $<.001$ \\
\hline & PML angle $\left({ }^{\circ}\right), * 2$ & $65.2 \pm 11.2$ & $50.2 \pm 26.2$ & NS (.088) \\
\hline & PA pressure $(\mathrm{mm} \mathrm{Hg})$ & $51.4 \pm 19.6$ & $35.0 \pm 10.1$ & $<.01$ \\
\hline & LA-LV PG (mm Hg) & - & $2.3 \pm 1.1$ & \\
\hline
\end{tabular}

Postoperatively, posterior leaflet tethering tended to be ameliorated, just as was the anterior leaflet tethering. $A M L$, Anterior mitral leaflet; $P M L$, posterior mitral leaflet; $L A$, left atrium; $L V$, left ventricular; $L V D d$, left ventricular diastolic diameter; $L V E F$, left ventricular ejection fraction; $M R$, mitral regurgitation; $N S$, not significant; $P A$, pulmonary artery; $P G$, pressure gradient.

\section{References}

1. Zhu F, Otsuji Y, Yotsumoto G, Yuasa T, Ueno T, Yu B, et al. Mechanism of persistent ischemic mitral regurgitation after annuloplasty: importance of augmented posterior mitral leaflet tethering. Circulation. 2005;112(9 suppl):I396-401.

2. Obase K, Komeda M, Okura H, Yoshida K. A new echocardiographic window to visualize mitral valve complex during mitral valve repair for functional mitral regurgitation. J Thorac Cardiovasc Surg. 2012;143:e42-4.
3. Masuyama S, Marui A, Shimamoto T, Nonaka M, Yoshida K, Komeda M, et al. Chordal translocation for ischemic mitral regurgitation may ameliorate tethering of the posterior and anterior mitral leaflets. J Thorac Cardiovasc Surg. 2008; 136:868-75

4. Ishikawa S, Ueda K, Kawasaki A, Neya K, Suzuki H. Papillary muscle sandwich plasty for ischemic mitral regurgitation: a new simple technique. J Thorac Cardiovasc Surg. 2008;135:1384-6.

\title{
Sutureless technique for recurrent pulmonary vein stenosis after pericardial patchplasty in an adult
}

\author{
Masanori Hirota, MD, PhD, Joji Hoshino, MD, Yasuhisa Fukada, MD, and Tadashi Isomura, MD, PhD, \\ Kanagawa, Japan
}

Although percutaneous balloon dilation is recommended for patients with pulmonary vein (PV) stenosis induced by catheter ablation for atrial fibrillation, surgical correction would be indicated for patients with stenosis refractory to interventional therapy. For such patients, conventional pericardial patchplasty for PV stenosis has been performed, resulting in recurrent stenosis requiring reoperation. A successful case of postoperative PV stenosis repaired using a sutureless technique in an adult is reported.

From the Department of Cardiovascular Surgery, Hayama Heart Center, Kanagawa, Japan.

Disclosures: Authors have nothing to disclose with regard to commercial support.

Received for publication Feb 17, 2012; revisions received March 13, 2012; accepted for publication April 4, 2012; available ahead of print Aug 17, 2012.

Address for reprints: Masanori Hirota, MD, PhD, Department of Cardiovascular Surgery, Hayama Heart Center, 1898-1 Shimoyamaguchi, Hayama, Kanagawa 240-0166, Japan (E-mail: hirota @ hayamaheart.gr.jp).

J Thorac Cardiovasc Surg 2012;144:1264-6

$0022-5223 / \$ 36.00$

Copyright (c) 2012 by The American Association for Thoracic Surgery

http://dx.doi.org/10.1016/j.jtcvs.2012.04.025

\section{CASE REPORT}

A 41-year-old man developed from recurrent PV stenosis induced by frequent catheter ablation for atrial fibrillation. Three-dimensional computed tomography showed restenosis of the bare metal stent in the left upper PV, complete occlusion of the left lower PV (LLPV), severe stenosis of the right upper $\mathrm{PV}$, and mild stenosis of the right lower $\mathrm{PV}$ (Figure 1, A).

Under cardioplegic arrest, the left side of the left atrium was opened, and the bilateral PVs were inspected. The intima had grown extensively over the stent, covering the orifice of the LLPV. After removal of the stent, the left upper PV, LLPV, and right upper PV were reconstructed using patchplasty with autologous pericardium treated with $0.6 \%$ glutaraldehyde. Postoperative 3-dimensional computed tomography demonstrated a successful outcome with wide opening of the bilateral PVs (Figure 1, B).

At 5 months after the initial operation, restenosis of 3 repaired PVs was confirmed by 3-dimensional computed tomography. Reoperation was performed for recurrence 

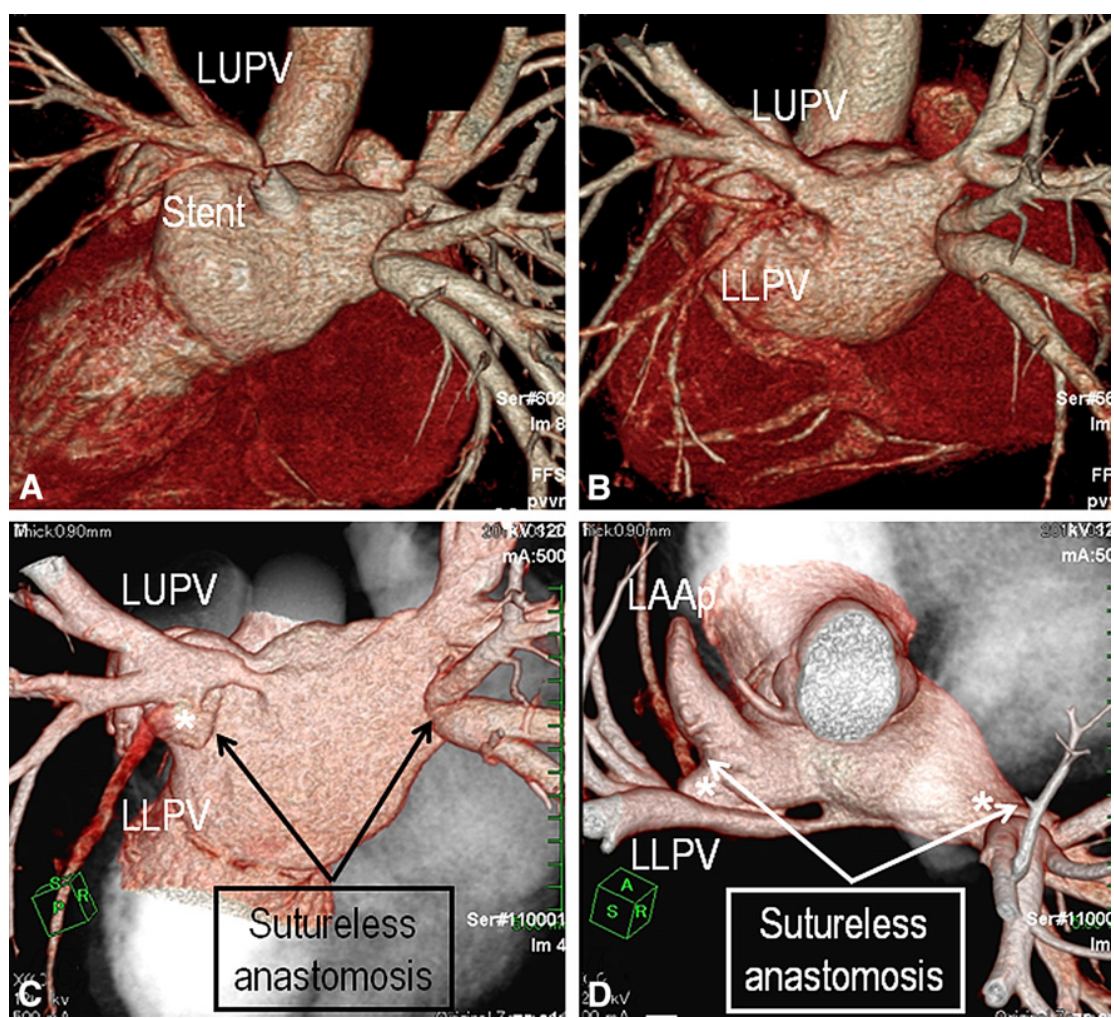

FIGURE 1. A, Preoperative 3-dimensional computed tomography showing severe stenosis of the left upper pulmonary vein (LUPV), complete occlusion of the left lower PV $(L L P V)$, severe stenosis of the right upper PV (RUPV), and mild stenosis of the right lower PV (RLPV). A bare metal stent was placed on the orifice of the LUPV. B, Stenotic regions were repaired using conventional pericardial patchplasty. C, D, After the sutureless technique, a bulging cavity (asterisk) can be seen between the left atrial appendage ( $L A A p)$ and the PV on the left. On the right, the root of the PVs has been enlarged by using the sutureless technique.

of PV stenosis. Excessive intima induced stenotic lesions over the anastomoses. The anterior walls of the left upper PV and LLPV were both excised from the orifice of the PVs toward the peripheral branch PVs. The left atrial appendage (LAAp) was opened obliquely, and the pericardium about $2 \mathrm{~cm}$ from the edge of the pulmonary venotomies was directly sewn to the LAAp to create a large bulging connection without touching the intima of the PVs (Figure 2). The anterior walls of the right upper PV and right lower PV were also excised, and the free edge of the left atrium was sewn to the pericardium.

An atriopericardial connection was detected by way of the LAAp (Figure 1, $C$ and $D$ ). At 7 months after the reoperation, he was asymptomatic during daily activities.
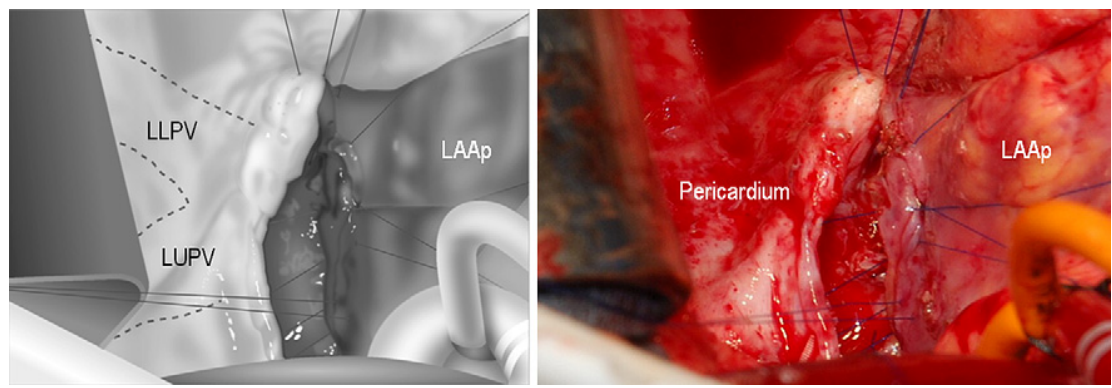

FIGURE 2. Anterior walls of both the left upper pulmonary vein $(L U P V)$ and left lower PV $(L L P V)$ have been excised from the orifice of the PVs toward the branch PVs. The left atrial appendage ( $L A A p)$ has been obliquely opened to create a large connection. The pericardium was sewn to the LAAp to overlap both the LUPV and LLPV. Anastomosis constructed with the pericardium and LAAp, without touching PV intima. Schematic drawing suggests the relationship between the PVs and the atriopericardial connection. 


\section{DISCUSSION}

PV stenosis appears frequently in neonates or infants with congenital heart disease such as total anomalous pulmonary venous connection. PV stenosis can be repaired using several surgical procedures, including a sutureless technique, ${ }^{1,2}$ patchplasty, ${ }^{3}$ excision of the stenosis, ${ }^{3}$ and reimplantation of the PV with direct anastomosis. ${ }^{4}$ The sutureless technique has evolved as a method to treat patients with recurrent PV stenosis developing after repair of total anomalous pulmonary venous connection. This technique requires no direct suturing of the PVs, enabling aggressive resection of the anterior wall of the segmental PV. Thus, the PV confluence can be created as wide as possible, even in complicated cases such as redo procedures. Additionally, oblique incision of the LAAp is key to creating a large atriopericardial anastomosis.

Although various congenital cases have been documented, to the best of our knowledge, only 1 adult case has been previously reported. ${ }^{3}$ In a 43 -year-old man with PV stenosis caused by idiopathic mediastinal fibrosis, pericardial patchplasty was performed for repair. ${ }^{3}$ After that report, we used conventional patchplasty for the first time. Subsequently, the sutureless technique was indicated for recurrent PV stenosis. However, a recent study reported that no significant difference could be found in the primary outcomes between the primary sutureless technique and conventional patchplasty in patients with a total anomalous pulmonary venous connection. ${ }^{1}$ Accordingly, our strategy was considered reasonable and proper for the present patient.

Currently, more than 40,000 cases of catheter ablation are attempted each year in the United States. ${ }^{5}$ PV stenosis induced by ablation occurs in $1 \%$ to $3 \%$ of patients, and most series have not reported the long-term implications or the potential need for surgical intervention. ${ }^{5}$ However, once PV occlusive disease has been established in neonates or infants, no matter how effective, the surgical relief could short term. ${ }^{1}$ These unfortunate patients are plagued by recurrent PV stenosis that eventually translates into mortality. ${ }^{1}$ In adult patients with PV stenosis, balloon angioplasty is recommended as the initial treatment, with stenting as the second choice. Finally, surgical correction would be indicated. Although the sutureless technique was effective in relieving complex forms of PV stenosis as in neonates and infants, it should be cautioned that the sutureless technique also has a known incidence of recurrent PV stenosis. ${ }^{1}$

\section{CONCLUSIONS}

A successful surgical case of recurrent PV stenosis after catheter ablation in an adult is reported. The sutureless technique is effective in preventing reactive hyperplasia of the intima over the connection between the left atrium and the PVs, especially for redo cases after failure of conventional patchplasty.

\section{References}

1. Viola N, Alghamdi AA, Perrin DG, Wilson GJ, Coles JG, Caldarone CA. Primary pulmonary vein stenosis: the impact of sutureless repair on survival. J Thorac Cardiovasc Surg. 2011;142:344-50.

2. Hickey EJ, Caldarone CA. Surgical management of post-repair pulmonary vein stenosis. Semin Thorac Cardiovasc Surg Pediatr Card Surg Annu. 2011;14: 101-8.

3. Van Son JA, Danielson GK, Puga FJ, Edwards WD, Driscoll DJ. Repair of congenital and acquired pulmonary vein stenosis. Ann Thorac Surg. 1995;60:144-50.

4. Pacifico AD, Mandke NV, McGrath LB, Colvin EV, Bini RM, Bargeron LM. Repair of congenital pulmonary venous stenosis with living autologous atrial tissue. J Thorac Cardiovasc Surg. 1985;89:604-9.

5. Holmes DR Jr, Monahan KH, Packer D. Pulmonary vein stenosis complicating ablation for atrial fibrillation. JACC Cardiovasc Interv. 2009;2:267-76.

\title{
Two-stage surgical strategy for aortoesophageal fistula: Emergent thoracic endovascular aortic repair followed by definitive open aortic and esophageal reconstruction
}

\author{
Prashanth Vallabhajosyula, MD, MS, Caroline Komlo, BS, Tyler Wallen, DO, and Wilson Y. Szeto, MD, \\ Philadelphia, $\mathrm{Pa}$
}

\footnotetext{
From the University of Pennsylvania Medical Center, Penn Presbyterian Medical Center, Philadelphia, Pa.

Disclosures: Authors have nothing to disclose with regard to commercial support.

Received for publication Jan 12, 2012; revisions received June 20, 2012; accepted for publication July 30, 2012; available ahead of print Sept 17, 2012.

Address for reprints: Wilson Y. Szeto, MD, University of Pennsylvania Medical Center, Penn Presbyterian Medical Center, 51 N 39th St, PHI Suite 2A, Philadelphia, PA 19104 (E-mail: Wilson.szeto@uphs.upenn.edu).

J Thorac Cardiovasc Surg 2012;144:1266-8

0022-5223/\$36.00

Copyright (C) 2012 by The American Association for Thoracic Surgery

http://dx.doi.org/10.1016/j.jtcvs.2012.07.084
}

Aortoesophageal fistula (AEF) is a rare complication, and is generally fatal without surgical intervention. ${ }^{1}$ Primary causes for AEF formation include foreign body ingestion, ruptured thoracic aortic aneurysms, endograft stenting of the thoracic aorta, advanced esophageal cancer, and surgical procedures involving the esophagus. ${ }^{1}$ Even though there are reports of thoracic endovascular stenting for the treatment of aortoesophageal fistula with early success, ${ }^{1,2}$ late failure and mortality is common. The 